\title{
The Assessment of the Severity of Patients with Generalized Intra-abdominal Infection: An Emphasis on the Predictive Value of Reducing Abdominal Perfusion Pressure in the Complex Treatment of Patients
}

\section{Kryvoruchko IA* and Olefir OS}

Kharkiv National Medical University of the Ministry of Health of Ukraine, Kharkiv, Ukraine

*Corresponding Author: Kryvoruchko IA, Kharkiv National Medical University of the Ministry of Health of Ukraine, Kharkiv, Ukraine.
Received: September 21, 2021

Published: October 06, 2021

(C) All rights are reserved by Kryvoruchko IA and Olefir OS.

\section{Abstract}

Background: An urgent task is to determine the prognosis of mortality in patients with complicated intra-abdominal infection at the stages of their complex treatment in the context of emergency abdominal surgery.

Methods: This study was based on data comparing severity indicators in 255 patients of both sexes, aged 18 to 70 years, who were operated on for secondary peritonitis in the same surgical hospital.

Results: By the criteria of Sepsis-3 patients without sepsis were 119 (46.7\%), with abdominal sepsis was diagnosed in 110 (43.1\%), and septic shock was diagnosed in $26(10.2 \%)$. The main finding of this study is that increased leukocyte, lactate, C-reactive protein levels and decreased systolic blood pressure, abdominal perfusion pressure 72 hours postoperatively were predictive factors for patients. It was shown that there was a strong negative relationship between intra-abdominal pressure and abdominal perfusion pressure $(r=-0.83, p=0.000)$, a positive correlation between the surgical approach $(r=0.88 ; p=0.000)$ and these increases of pressure values were correlated with the deterioration of the patients' condition according to the APACHE II and SOFA scores severity. It was also confirmed that the risk of developing abdominal compartment syndrome statistically significantly $(\mathrm{p}=0.000)$ increases in the presence of intestinal paresis (odd ratio $=3.3$, 95\% CI 1.5-3.9), the numbers of re-laparotomies (odd ratio $=7.84$, 95\% CI 4.8-8.5), and massive infusion therapy (odd ratio $=1.8,95 \% \mathrm{CI} 1.1-2.9$ ), and its will be able to lead to the development of acute respiratory distress syndrome (odd ratio $=11.6,95 \%$ CI 8.7-14.1), cardiogenic pulmonary edema after surgery (odd ratio 2.6 , 95\% CI 1.8-3.9), and postoperative delirium (odd ratio $=2.2,95 \%$ CI 1.6-3.1).

Conclusions: Evaluation of effective biomarkers of patient severity had to use in emergency abdominal surgery to improve treatment outcomes.

Keywords: Generalized Intra-abdominal Infection; Abdominal Sepsis; Septic Shock; Biomarkers; Intra-Abdominal Hypertension; Abdominal Compartment Syndrome; Results

\section{Introduction}

Intra-abdominal hypertension (IAH) is an important outcomepredictor in critically ill patients [1,2]. Abdominal compartment syndrome (ACS), as a component of multiple organs disorders, is observed in at least $36 \%$ of patients in intensive care units [3]. In this case, the mortality rate reaches $70-80 \%$ [4], and abdominal

Citation: Kryvoruchko IA and Olefir OS. "The Assessment of the Severity of Patients with Generalized Intra-abdominal Infection: An Emphasis on the Predictive Value of Reducing Abdominal Perfusion Pressure in the Complex Treatment of Patients". Acta Scientific Medical Sciences 5.11 (2021): 17-26. 
perfusion pressure (APP) is considered the best endpoint for resuscitation [5]. Among the pathogenic mechanisms of the formation of ACS, the most important is the development of microcirculatory insufficiency due to a decrease in perfusion pressure [6,7], impaired endothelial function, the imbalance between end othelium-relaxing factors and vasoconstrictors $[8,9]$. This largely determines the severity of the development of intra-abdominal hypertension during operations on the abdominal organs [10]. Large volume fluid resuscitation is very common in medical ICU patients presenting with sepsis, shock, and other inflammatory conditions like pancreatitis and it is one of the major risk factors for the development of intraabdominal hypertension [11-13]. Unresolved issues are the identification of the severity and risk factors of ACS in intra-abdominal infections, including those complicated by abdominal sepsis [14]. The multifactorial mechanism of ACS development requires not only timely detection and elimination, but also prevention of the influence of endogenous mechanisms of ACS formation $[15,16]$.

\section{The Aim}

To determine the role of risk factors and the degree of their influence on the development of ACS for the development of an algorithm for individualized treatment of patients with generalized intra-abdominal infection. The effectiveness of various indicators in predicting mortality among patients was also assessed.

\section{Materials and Methods Design of study}

Over 10 years from January 2011 to January 2021 period a retrospective analysis of risk factors for the development of ACS in 255 patients admitted with generalized intra-abdominal infection (IAI) with surgical pathology of the abdominal organs was carried out.

\section{Inclusion criteria}

The study included men and women over 18 and under 70 years of age who were admitted to hospital with IAI without and with sepsis or septic shock within 24-72 hours and more of admission to the surgery or intensive care unit. All patients had been appreciated the Sepsis-3 criteria [17]. All of these were operated on urgently.

\section{Exclusion criteria}

Comorbidity with acute myocardial infarction and stroke; IAI caused by the cancer of the hollow organ; post-resuscitation illness due to stopping effective blood circulation; pregnancy; cancer in anamnesis; diseases resuscitation status due to refractory shock.

All patients were done surgery with effective source control, supporting appropriate antibiotics, resuscitation, and organ support therapy. Patients were divided into two groups: in the $1^{\text {st }}$ included those with a positive outcome (discharged, $\mathrm{n}=216$ ), and in the $2^{\text {nd }}$ those with adverse outcomes (died, $n=39$ ).

In the study of patients, the following data were collected: patient, characteristics: age, gender, body mass index (BMI), assessment of severity according to the APACHE II score and assessment of organ dysfunction according to the SOFA score, the indicators for which were calculated on the ClinCalc.com website. Also for each enrolled patient were collected: personal data, admission data; comorbidity (Charlson Comorbidity Index (CCI), laboratory analysis (WBC count, platelets, total bilirubin, creatinine, lactate, C-reactive protein (CRP), procalcitonin, hematocrit) on the first admission day and after $72 \mathrm{~h}$; In the dynamics of the treatment of patients after surgery, studies were carried out systolic blood pressure (SBP), IAP, APP, and also computed for each patient the following scores, validated for IAI and abdominal sepsis: APACHE II and SOFA, nature of treatment (mechanical ventilation, inotropic support, artificial kidney), nature of complications, AGI assessment (degree), results (30-day mortality).

The registration of IAP was determined indirectly by measuring the pressure in the bladder according to I.L. Kron., et al. (1984) [18]. Patients were screened for IAH (defined as IAP $\geq 12 \mathrm{mmHg}$ ) with the Foley-Manometer method (Denmark). We have used the classification of the World Society of Abdominal Compartment Syndrome (WSACS, 2007) to assess the level of IAH with the recommendations: I degree IAP was registered at IAH $12-15 \mathrm{~mm} \mathrm{Hg}$ (16.3-20.4 cm H $\mathrm{Cm}_{2}$ ); II degree - 16-20 mm Hg (21.76-33.2 $\mathrm{cm} \mathrm{H}_{2} 0$ ); III degree - 21-25 mm Hg (28.56-34 cm H $\mathrm{H}_{2}$ ); IV degree - > $25 \mathrm{~mm}$ $\mathrm{Hg}\left(>34 \mathrm{~cm} \mathrm{H}_{2} \mathrm{O}\right)$. APP was calculated using the formula:

$\mathrm{APP}=\mathrm{MAP}-\mathrm{IAP},(1)$

Note: MAP is mean arterial pressure, IAP - intra-abdominal pressure.

MAP = diastolic blood pressure $+1 / 3$ pulse blood pressure, $(2)$ 
Note: Blood pressure is pulse = blood pressure is systolic - blood pressure is diastolic.

Complications were registered according to the classification of the European Society of Anesthesiology and Intensive Care [19] with some additions that were adapted to the conditions of our clinic which included the following: acute kidney injury; acute respiratory distress syndrome (ARDS); anastomotic leak; arrhythmias; circulatory arrest; cardiogenic pulmonary edema; postoperative delirium; myocardial infarction; pneumonia; intestinal paresis more than $72 \mathrm{~h}$ after surgery; postoperative bleeding; pulmonary embolism; acute cerebrovascular accident; infectious complications in the operation; type of primary operation: planned or urgent; massive resuscitation: more than 5 liters in $24 \mathrm{~h}$; the number of required re-laparotomies.

\section{Statistical analyses}

Statistical data processing was performed using the trial version of STATISTICA 13.3 EN. Initially, statistical analysis was performed using descriptive statistics. Using the Tukey test, the presence of emissions was checked and the normality of the distributions (Shapiro-Wilk test) of the selected indicators was assessed. Continuous data were presented as Me (Q1; Q3), where Me is the median, Q1 and Q3 is the interquartile range (IQR). The nonparametric Mann-Whitney test was used for pairwise comparisons of means in independent groups. Zero hypotheses (H0) in statistical tests were rejected at a significance level of $\mathrm{p}<0.05$. When predicting the outcome of treatment, the greatest accuracy and adequacy in terms of a posteriori classification was obtained by discriminant analysis. Prediction of treatment was carried out not only with the use of multidimensional statistical methods but also with the help of various scores of the severity of the condition or disorders of the physiological condition of the patient in abdominal sepsis: APACHE II and SOFA scores in the dynamics of the treatment.

\section{Results}

The patients were divided according to the severity of the condition which was determined by the criteria of Sepsis-3: patients without sepsis were 119 (46.7\%), with abdominal sepsis was diagnosed in 110 (43.1\%), and septic shock was diagnosed in 26 $(10.2 \%)$ (Figure 1$)$. The causes of IAI were secondary peritonitis with perforated peptic ulcer, perforation of the vermiform appendix, perforation of the large colon in diverticulitis, acute intestinal obstruction with generalized purulent peritonitis, strangulated ventral hernia with generalized purulent peritonitis, failure of intraintestinal and gastrointestinal anastomoses (Figure 2). The study was dominated by men (74.1\%).

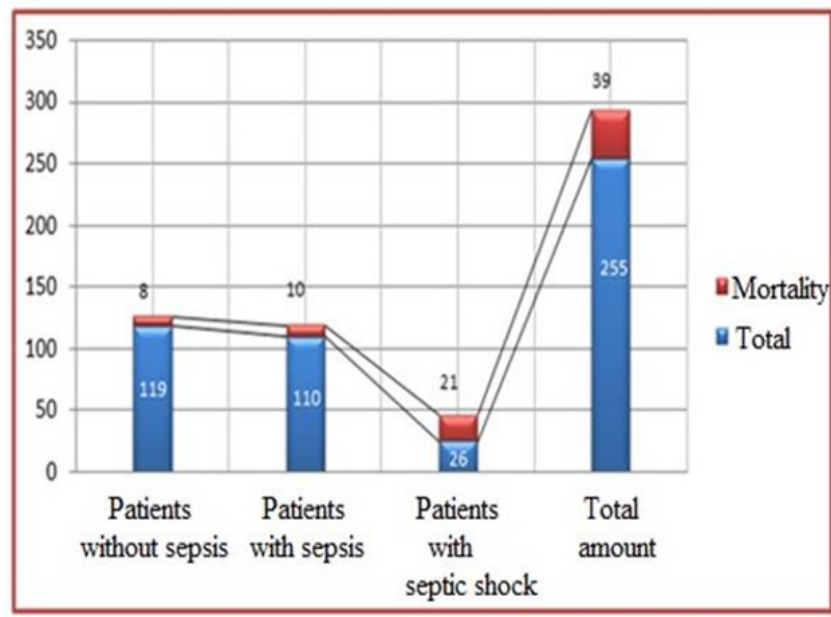

Figure 1: Distribution of patients with IAI.

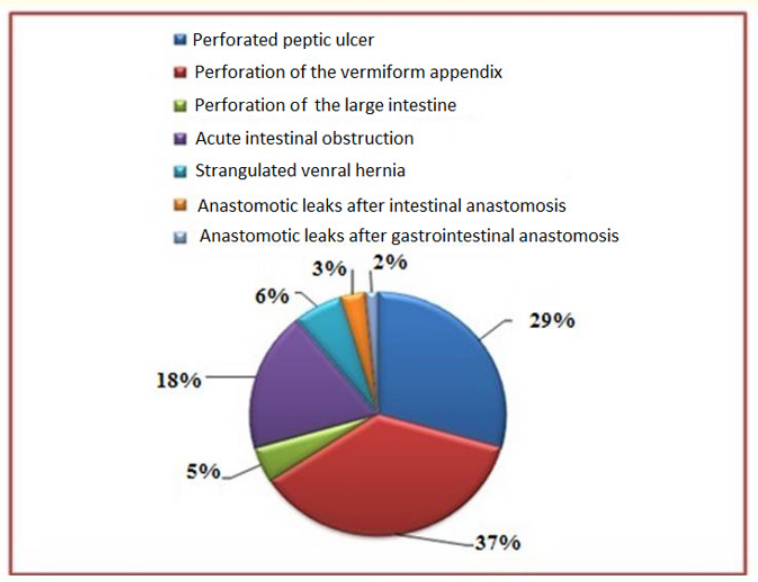

Figure 2: The causes of IAI.

The results of the distribution of patients by tactical approach by severity and mortality are presented in table 1 . 
The Assessment of the Severity of Patients with Generalized Intra-abdominal Infection: An Emphasis on the Predictive Value of Reducing Abdominal Perfusion Pressure in the Complex Treatment of Patients

\begin{tabular}{|c|c|c|c|c|c|c|}
\hline \multirow[b]{2}{*}{ Indicators } & \multicolumn{2}{|c|}{ Before surgery } & \multirow[b]{2}{*}{$\mathbf{P}$} & \multicolumn{2}{|c|}{ After 72 hours } & \multirow[b]{2}{*}{$P$} \\
\hline & $\begin{array}{l}\text { Positive } \\
\text { outcome } \\
(n=216)\end{array}$ & $\begin{array}{l}\text { Adverse outcome } \\
\quad(n=39)\end{array}$ & & $\begin{array}{l}\text { Positive } \\
\text { outcome } \\
(n=216)\end{array}$ & $\begin{array}{l}\text { Adverse outcome } \\
\quad(n=39)\end{array}$ & \\
\hline $\begin{array}{l}\text { Ages, } \\
\text { Me [IQR] }\end{array}$ & $\begin{array}{c}53 \\
{[18-70]}\end{array}$ & $\begin{array}{c}51 \\
{[23-69]}\end{array}$ & 0.112 & - & - & \\
\hline $\begin{array}{l}\text { BMI, } \mathrm{kg} / \mathrm{m}^{2}, \\
\text { Me [IQR] }\end{array}$ & $\begin{array}{c}25 \\
{[22.2-29.4]}\end{array}$ & $\begin{array}{c}31 \\
{[22.9-34.5]}\end{array}$ & 0.003 & - & - & \\
\hline $\begin{array}{l}\text { CCI } \\
\text { Me [IQR] }\end{array}$ & $\begin{array}{c}2 \\
{[1-4]}\end{array}$ & $\begin{array}{c}5 \\
{[2-9]}\end{array}$ & 0.007 & & & \\
\hline $\begin{array}{l}\text { WBC count } \\
\left(\times 10^{9} / 1\right) \\
\text { Me [IQR] }\end{array}$ & $\begin{array}{c}14.7 \\
{[12.4-21.3]}\end{array}$ & $\begin{array}{c}19.8 \\
{[13.2-22.2]}\end{array}$ & 0.000 & $\begin{array}{c}14.6 \\
{[12.3-24.1]}\end{array}$ & $\begin{array}{c}24.8 \\
{[17.4-28.2]}\end{array}$ & 0.000 \\
\hline $\begin{array}{l}\text { Platelets }\left(\times 10^{3} / \mathrm{l}\right) \\
\text { Me [IQR] }\end{array}$ & $\begin{array}{c}292.22 \\
{[232.8-329.6]}\end{array}$ & $\begin{array}{c}282.4 \\
{[256.2-359.7]} \\
\end{array}$ & 0.056 & $\begin{array}{c}264.8 \\
{[224.4-311.3]}\end{array}$ & $\begin{array}{c}187.5 \\
{[158.2-215.1]} \\
\end{array}$ & 0.000 \\
\hline $\begin{array}{l}\text { Hematocrit (\%), } \\
\text { Me [IQR] }\end{array}$ & $\begin{array}{c}38.2 \\
{[35.8-46.1]} \\
\end{array}$ & $\begin{array}{c}39.1 \\
{[36.4-46.3]} \\
\end{array}$ & 0.168 & $\begin{array}{c}38.6 \\
{[35.4-49.5]} \\
\end{array}$ & $\begin{array}{c}44.8 \\
{[36.4-46.6]}\end{array}$ & 0.004 \\
\hline $\begin{array}{l}\text { Creatinine (mg/dl), } \\
\text { Me [IQR] }\end{array}$ & $\begin{array}{c}0.87 \\
{[0.76-1.109]} \\
\end{array}$ & $\begin{array}{c}0.89 \\
{[0.72-0.94]} \\
\end{array}$ & 0.104 & $\begin{array}{c}0.113 \\
{[0.88-1.543]} \\
\end{array}$ & $\begin{array}{c}1.92 \\
{[1.46-2.21]} \\
\end{array}$ & 0.000 \\
\hline $\begin{array}{l}\text { Total bilirubin } \\
(\mu \mathrm{mol} / \mathrm{l})\end{array}$ & $\begin{array}{c}24.5 \\
{[16.8-52.4]}\end{array}$ & $\begin{array}{c}24.4 \\
{[21.2-64.6]}\end{array}$ & 0.121 & $\begin{array}{c}26.5 \\
{[14.5-58.2]}\end{array}$ & $\begin{array}{c}59.5 \\
{[28.3-108.2]}\end{array}$ & 0.000 \\
\hline $\begin{array}{l}\text { Lactate (mmol/l), } \\
\text { Me [IQR] }\end{array}$ & $\begin{array}{c}2.1 \\
{[1.6-2.8]}\end{array}$ & $\begin{array}{c}2.6 \\
{[1.8-6.9]} \\
\end{array}$ & 0.000 & $\begin{array}{c}3.4 \\
{[1.9-7.6]} \\
\end{array}$ & $\begin{array}{c}9.9 \\
{[5.2-12.3]}\end{array}$ & 0.000 \\
\hline $\begin{array}{l}\text { PCT } \\
(\mathrm{pg} / \mathrm{ml}) \\
\mathrm{Me}[\mathrm{IQR}]\end{array}$ & $\begin{array}{c}2.125 \\
{[0.125-71.212]}\end{array}$ & $\begin{array}{c}2.234 \\
{[0.116-80.143]}\end{array}$ & 0.358 & $\begin{array}{c}5.881 \\
{[2.117-86.021]}\end{array}$ & $\begin{array}{c}10.115 \\
{[3.426-151.113]}\end{array}$ & 0.000 \\
\hline $\begin{array}{l}\text { CRP } \\
\text { (mg/l), } \\
\text { Me [IQR] }\end{array}$ & $\begin{array}{c}134 \\
{[121-166]} \\
\end{array}$ & $\begin{array}{c}185 \\
{[130-201]} \\
\end{array}$ & 0.000 & $\begin{array}{c}151 \\
{[148-176]} \\
\end{array}$ & $\begin{array}{c}201 \\
{[160-213]} \\
\end{array}$ & 0.000 \\
\hline $\begin{array}{l}\text { SBP } \\
\text { (mm Hg), } \\
\text { Me [IQR] }\end{array}$ & $\begin{array}{c}115 \\
{[90-130]}\end{array}$ & $\begin{array}{c}85 \\
{[70-100]} \\
\end{array}$ & 0.000 & $\begin{array}{c}130 \\
{[90-155]}\end{array}$ & $\begin{array}{c}70 \\
{[70-100]} \\
\end{array}$ & 0.000 \\
\hline $\begin{array}{l}\text { APP } \\
\text { (mm Hg), } \\
\text { Me [IQR] }\end{array}$ & $\begin{array}{c}72 \\
{[64-76]} \\
\end{array}$ & $\begin{array}{c}55 \\
{[51-66]}\end{array}$ & 0.000 & $\begin{array}{c}70 \\
{[64-78]} \\
\end{array}$ & $\begin{array}{c}52 \\
{[50-66]} \\
\end{array}$ & 0.000 \\
\hline $\begin{array}{l}\text { AGI grade, } \\
\text { Me [IQR] }\end{array}$ & $\begin{array}{c}1 \\
{[1-3]}\end{array}$ & $\begin{array}{c}3 \\
{[2-3]}\end{array}$ & 0.000 & - & - & \\
\hline $\begin{array}{l}\text { APACHE II score, } \\
\text { Me [IQR] }\end{array}$ & $\begin{array}{c}13 \\
{[10-22]}\end{array}$ & $\begin{array}{c}21 \\
{[14-28]}\end{array}$ & 0.000 & $\begin{array}{c}14 \\
{[12-22]}\end{array}$ & $\begin{array}{c}26 \\
{[16-36]}\end{array}$ & 0.000 \\
\hline $\begin{array}{l}\text { SOFA score, } \\
\text { Me [IQR] }\end{array}$ & $\begin{array}{c}9 \\
{[7-11]}\end{array}$ & $\begin{array}{c}12 \\
{[8-14]}\end{array}$ & 0.000 & $\begin{array}{c}9 \\
{[8-12]}\end{array}$ & $\begin{array}{c}14 \\
{[9-16]}\end{array}$ & 0.000 \\
\hline
\end{tabular}

Table 1: Demographic, clinical and laboratory characteristics of patients with IAI.

Note: P - Mann-Whitney test. 
At the first stage, all the material was processed using variational statistic methods. These studies showed that there is a strong negative relationship between IAP and APP: $r=-0.83, p=0.000$ (Figure 3). The established correlation also dependence reflected the dynamics of the patients' condition: with the decrease in IAP, the APP increased, which possibly reflected the normalization of splanchnic circulation as a result of complex treatment of patients. As a result of the study of the IAP dynamics in the patients of the study groups, a positive correlation was established between the IAP level and the surgical approach ( $r=0.88$; $p=0.000)$. The increase in IAP values correlated with the deterioration of the patients' condition according to the APACHE II and SOFA scores (respectively, $r=0.73, p<0.003, r=0.81, p=0.000$ ), but increase and maintenance of IAP up to $25 \mathrm{~mm} \mathrm{Hg}$ and higher testified to the development of ACS.

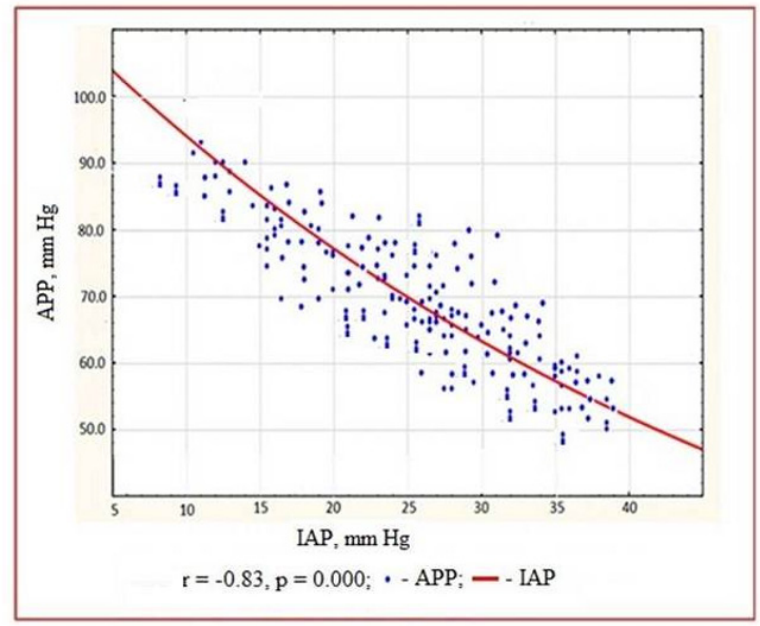

Figure 3: Relationship between the level of intra-abdominal pressure (IAP) and abdominal perfusion pressure.

A total of 81 (31.8\%) postoperative complications were reported, of which emergency surgery, infectious complications in the operation, intestinal paresis for more than $72 \mathrm{~h}$, the number of re-laparotomies after primary surgery, massive infusion therapy of more than 5 liters in $24 \mathrm{~h}$ of resuscitation and pneumonia were the most common. The structure of complications is shown in Figure 4 . In the group of patients with complications after surgery the mean age was statistically significantly higher (62 years [57-70]

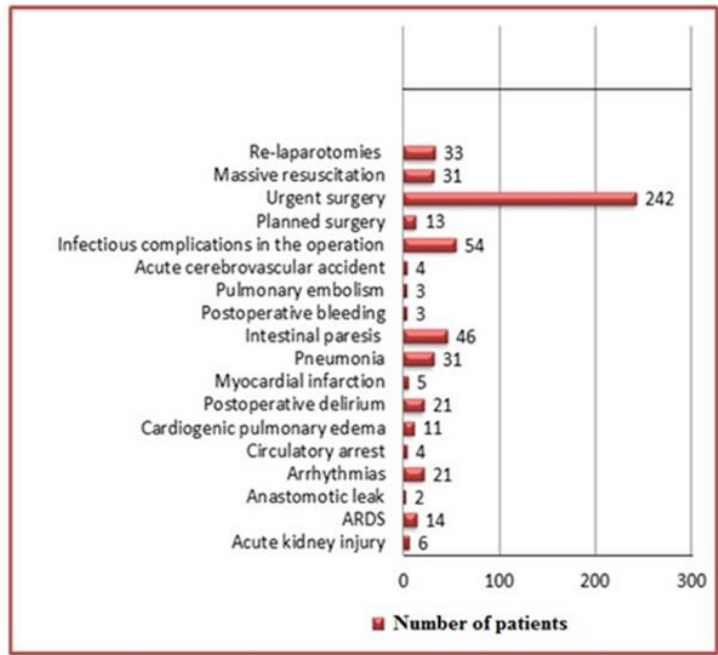

Figure 4: Postoperative complications rate.

vs. 56 years [23-69] in patients without complications $(\mathrm{p}<0.001)$. In the incidence of postoperative complications, the difference between men and women was less pronounced compared to mortality but they were more common in men. As well as mortality, the incidence of postoperative complications increased with the nature of the operation and the injury of the surgery $(\mathrm{p}<0.05)$. Also, the incidence of postoperative complications was higher in groups of patients with a Charlson Comorbidity Index of more than 4 , regardless of the type of disease.

The coefficients of the logistic regression equation are presented in table 2 . The data that is presented indicate the contribution of each complication to the mortality of these patients. In some patients, the postoperative period was accompanied by the development of two or more complications, while with the increase in the number of complications to increase in mortality occurred, and in the presence of four complications or more, a fatal outcome was observed in $100 \%$ of cases. Analysis of our results showed that with an increase in traumatism during surgery, the risk of postoperative complications increases $(\mathrm{OR}=3.1)$. Perhaps this fact contributed to the occurrence of such complications as Infectious complications after surgery $(\mathrm{OR}=3.71)$, intestinal paresis after surgery $(\mathrm{OR}=3.3$ ), acute respiratory distress syndrome after surgery (ARDS) $(O R=11.6)$, intestinal paresis more than $72 \mathrm{~h}$ after surgery $(\mathrm{OR}=3.3)$, etc. $($ Table 2$)$.

Citation: Kryvoruchko IA and Olefir OS. "The Assessment of the Severity of Patients with Generalized Intra-abdominal Infection: An Emphasis on the Predictive Value of Reducing Abdominal Perfusion Pressure in the Complex Treatment of Patients". Acta Scientific Medical Sciences 5.11 (2021): $17-26$. 
The Assessment of the Severity of Patients with Generalized Intra-abdominal Infection: An Emphasis on the Predictive Value of Reducing Abdominal Perfusion Pressure in the Complex Treatment of Patients

\begin{tabular}{|l|c|c|c|c|c|c|}
\hline Variable & Coefficient & $\begin{array}{c}\text { Standard } \\
\text { deviation }\end{array}$ & Wald test & p & Odds ratio & 95\% CI \\
\hline Emergency surgery & 0.63 & 0.16 & 16.3 & 0.000 & 2.1 & $1.4-2.9$ \\
\hline Injury of operation & 0.91 & 0.17 & 32.6 & 0.000 & 3.1 & 3.71 \\
\hline $\begin{array}{l}\text { Infectious complications after } \\
\text { surgery }\end{array}$ & 1.12 & 1.84 & 38.4 & 0.000 & $1.8-4.1$ \\
\hline $\begin{array}{l}\text { Number of re-laparotomies after } \\
\text { primary surgery }\end{array}$ & 1.87 & 1.97 & 47.9 & 0.000 & 7.84 & $4.8-8.5$ \\
\hline Massive infusion therapy & 0.59 & 0.14 & 14.6 & 0.000 & 1.8 & $1.1-2.9$ \\
\hline Pneumonia after surgery & 0.52 & 0.12 & 12.3 & 0.012 & 1.6 & $0.8-2.6$ \\
\hline ARDS & 2.2 & 2.45 & 53.2 & 0.000 & 11.6 & $8.7-14.1$ \\
\hline Cardiogenic pulmonary edema & 0.99 & 0.17 & 32.8 & 0.000 & 2.6 & $1.8-3.9$ \\
\hline Postoperative delirium & 0.77 & 0.18 & 18.1 & 0.000 & 2.2 & $1.6-3.1$ \\
\hline Intestinal paresis & 1.2 & 1.12 & 19.8 & 0.000 & 3.3 & $1.9-4.2$ \\
\hline
\end{tabular}

Table 2: Coefficients of the logistic regression equation.

The data obtained made it possible to confirm the role of the factors of operational aggression in the development of the abdominal compartment syndrome, which leads to an increase in IAP of more than $12 \mathrm{~mm} \mathrm{Hg}$. and a decrease in the APP less than $60 \mathrm{~mm}$ $\mathrm{Hg}$. These data reflected the presence of intra-abdominal hypertension in violation of microcirculation in the abdominal organs in the dependence of SOFA and APACHE II scores on the APP level before surgery and $72 \mathrm{~h}$ after. At the same time, an increase in the blood lactate level of more than $2.5 \mathrm{mmol} / \mathrm{l}$ (AUROC 0.834) was noted both before and after the surgery and these changes were most pronounced in patients with the adverse outcome which reflected the presence of violations combined by the circulatory. The persistence of IAH by day 3 was able to discriminate between survivors and non-survivors patients on our data.

\section{Discussion}

Due to the fact that the abdominal cavity is a closed space, an increase in IAP can have a negative effect on the function of the digestive tract, respiratory, cardiovascular, urinary, and central nervous systems. Such a condition is defined as an ACS and without special treatment can lead to a complete loss of functional activity of the patient's organs and systems and death. Timely reduction of IAH leads to the reverse development of disorders. A whole group of reasons, post-traumatic and postoperative complications can lead to the development of abdominal compression syndrome. The clinical picture and physical examination of the abdomen are insufficient for the diagnosis of intra-abdominal hypertension. Measuring the pressure in the abdominal cavity by assessing the pressure in the bladder is an accurate and simple method, which can be performed in the most severe patient. Treatment of abdominal compression syndrome includes a number of therapeutic measures, if ineffective, early surgical decompression is indicated. Even with timely treatment of this syndrome, there is a high mortality rate in patients. The duration of IAH in combination with an acute onset of the disease has a greater prognostic value plays an important role in the realization of the effect of increased IAP and can lower the threshold for the development of ACS [20].

In the present study, the baseline values of IAP and APP were significantly higher in the group of patients with adverse outcomes compared to patients in a group with a positive outcome. The fact that IAI can be especially complicated by sepsis and septic shock did not change our understanding of the causes of complicated IAI, nor that there were many causes of increased IAP. This seems to be very logical since the volume of infected fluid contained in the abdominal cavity as a result of the prevalence of the pathological process takes up a larger volume of the total volume of the abdominal cavity than in the patients with uncomplicated IAI and IAP is

Citation: Kryvoruchko IA and Olefir OS. "The Assessment of the Severity of Patients with Generalized Intra-abdominal Infection: An Emphasis on the Predictive Value of Reducing Abdominal Perfusion Pressure in the Complex Treatment of Patients". Acta Scientific Medical Sciences 5.11 (2021): $17-26$. 
The Assessment of the Severity of Patients with Generalized Intra-abdominal Infection: An Emphasis on the Predictive Value of Reducing Abdominal Perfusion Pressure in the Complex Treatment of Patients

above the pressures that cause IAH ( $\geq 12 \mathrm{~mm} \mathrm{Hg}$ ) according to the definition of the WSACS [21-23] in this patients. At the same time, it is known that an increase in IAP to $12 \mathrm{~mm} \mathrm{Hg}$ does not cause clinically significant changes, but special attention should be paid to the presence of additional pathologies in specific patients. The influence of increased IAP on the functions of internal organs was described as early as the $19^{\text {th }}$ century. So, in 1876 , E. Wendt in his publication [24] reported undesirable changes in the body due to an increase in pressure in the abdominal cavity. Subsequently, individual publications of scientists described violations of hemodynamics, respiration and renal function associated with increased IAP. However, only relatively recently its negative effects were recognized, namely the development of abdominal compartment syndrome with a mortality rate of up to $42-68 \%$, and in the absence of appropriate treatment reaching 100\% [25]. Underestimation or neglect of the clinical significance of IAP and IAH are circumstances that increase the number of adverse outcomes in the intensive care unit [26-28]. In recent decades, it has been increasingly discussed that ACS is one of the main factors in the disruption of vital body systems and is a pathological condition with a high risk of adverse outcomes that requires timely diagnosis and immediate treatment. Symptom complex in ACS is nonspecific; its manifestation can occur with a large number of surgical and non-surgical pathologies, it has often led to oliguria or anuria, a high level of central venous pressure, pronounced tachypnea and a decrease in oxygen saturation, profound impairment of consciousness, postoperative intestinal paresis, a drop in cardiac activity what can be interpreted as manifestations of multiple organ failure like in patients with the traumatic disease, heart failure or severe infectious process. Postoperative mortality in patients urgently operated on for complicated intra-abdominal infection remains quite high due to the frequent development of multiple disorders of organs after surgery. In recent decades, it has been increasingly discussed that ACS is one of the main factors in the disruption of vital body systems and is a pathological condition with a high risk of adverse outcomes that requires timely diagnosis and immediate treatment. From the analysis of the coefficients of the logistic regression model, it follows that complicated IAI statistically significantly $(p<0.01)$ increases the risk of developing infectious complications after surgery (OR $=3.71,95 \%$ CI 1.8-4.1), as our study was shown. Significant risk factors for the development of infectious complications include intraoperative hypotension, organ hypoperfusion with an increase in
IAP. We were noticed that many episodes of hypotension had been significantly increased the risk of complications. The total duration of arterial hypotension in patients with a complicated postoperative period was significantly longer than in a favorable course. We associated this with a decrease in blood flow in the mesenteric vessels and the development of ischemia of the small intestine. Our study has also shown an increase in blood lactate in patients with poor outcomes 72 hours after surgery, despite the elimination of the source of infection. We explained this by accumulation and after elimination of IAH a massive intake of underoxidized decomposition products into the bloodstream with the development of secondary reperfusion injury. Thus, the increase in blood markers such as lactate can be considered as evidence of the development of ischemia in the intraoperative period [29]. Hypoperfusion, which occurs with an increase in IAP, a decrease in splanchnic blood flow, promotes the development of tissue hypoxia. It was found that even with a relatively low IAP, there is an increase in malonic dialdehyde and with a decrease in the intramucosal pH of the stomach during hypotension and this circumstance was associated with the development of oxidative stress due to ischemic and reperfusion injury against the background of intra-abdominal hypertension [30]. Nevertheless, it is important to emphasize that the IAP in the group of patients with an adverse outcome in our observations was significantly lower than in the group of patients with a positive outcome. The correlation analysis revealed that the risk of developing ACS statistically significantly $(\mathrm{p}<0.0001)$ increased in the presence of intestinal paresis ( $\mathrm{OR}=3.3,95 \%$ CI 1.5-3.9), depended on the numbers of re-laparotomies (OR $=7.84,95 \% \mathrm{CI}$ 4.8-8.5) and using massive infusion therapy (OR $=1.8,95 \%$ CI 1.12.9). It was be able to lead to the development of ARDS (OR $=11.6$, 95\% CI 8.7-14.1), cardiogenic pulmonary edema (OR $=2.6,95 \% \mathrm{CI}$ 1.8-3.9), and postoperative delirium ( $\mathrm{OR}=2.2,95 \% \mathrm{CI} 1.6-3.1)$ after surgery. The abdominal organs are very sensitive to secondary reperfusion injury, which is associated with impaired blood flow in the mesenteric vessels, simultaneous ischemic and free radical damage, and a violation of the mucous barrier. This is accompanied by the movement of microorganisms and intestinal endotoxin into the portal and general circulation.

The studies carried out confirmed the fact that the data obtained indicate the need to continue studies to assess the validity of these indicators when conducting targeted intraoperative and 
postoperative treatment of patients who underwent surgical interventions for complicated intra-abdominal infection in order to identify significant risk factors for the development of complications in order to standardize surgical methods and intensive care in the treatment of these patients.

\section{Conclusion}

The results from an ongoing study and study of APP in IAI patients with and without abdominal sepsis have shown that the frequency of IAH is high in complicated IAI and mortality was also high and correlated with severity scores. It was keeping the IAH up to the third day after surgery makes it possible to distinguish between a positive result in patients who survived and those who did not. The presence of low abdominal perfusion pressure $(<60 \mathrm{~mm}$ $\mathrm{Hg}$ ) allows preliminary identification of a group of patients with a high risk of mortality from the first days after surgery against the background of intensive treatment of patients. The close monitoring of intra-abdominal pressure and especially abdominal perfusion pressure looks warranted in patients with generalized intraabdominal infection including those with abdominal sepsis.

\section{Authors' Contribution}

A - Study design;

B - Data collection;

C - Statistical analysis;

D - Data interpretation;

E - Manuscript preparation;

F - Literature search;

G - Funds collection

All authors have contributed equally to this work. All authors have read and approved the final manuscript.

\section{Compliance with Ethical Standards}

The work has been cleared by the Ethics Committee of Kharkiv National Medical University, Ukraine (the protocol №2, March 12, 2021).

\section{Competing Interests}

The authors declare that they have no competing interests.

\section{Informed Consent Process}

Informed consent was obtained from all participants included in the study.

\section{Acknowledgments}

The authors have thanked the Rector of the Kharkiv National Medical University, Professor Kapustnyk V.A., and the Head of Academic Council, Professor Lisovyi V. M. for supporting this study. The authors are very grateful to the Municipal noncommercial enterprise of Kharkiv regional council «Regional Clinical Hospital» for providing all the diagnostic and surgical equipment used in this study.

\section{Funding Sources}

This research was part of the research work of the Kharkiv National Medical University "Improvement and development of methods for diagnosis and surgical treatment of diseases and injuries of the abdominal cavity and chest, vessels of the upper and lower extremities using mini-invasive techniques in patients at high risk of postoperative complications" The number of state registration is 0116u00499. Funding from the state budget.

\section{Data and Materials Availability}

All data associated with this study are present in the paper.

\section{Bibliography}

1. Sugrue M., et al. "Intra-abdominal hypertension is an independent cause of postoperative renal impairment". Archives of Surgery 134 (1999) : 1082-1085.

2. Malbrain Manu LNG. "Is it wise not to think about intraabdominal hypertension in the ICU?" Current Opinion in Critical Care 10 (2004): 132-145.

3. Hunter JD and Damani Z. "Intra-abdominal hypertension and the abdominal compartment syndrome". Anaesthesia 59 (2004): 899-907.

4. Malbrain ML., et al. "Incidence and prognosis of intraabdominal hypertension in a mixed population of critically ill patients: a multiple-center epidemiological study". Critical Care Medicine 33 (2005): 315-322. 
5. Cheatham ML., et al. "Abdominal perfusion pressure: a superior parameter in the assessment of intra-abdominal hypertension". Journal of Trauma 49 (2000): 621-626; discussion 626-627.

6. Wise R., et al. "Awareness and knowledge of intra-abdominal hypertension and abdominal compartment syndrome: results of an international survey". Anesthesiology Intensive Therapy 47 (2015): 14-29.

7. Kimball EJ., et al. "Survey of intensive care physicians on the recognition and management of intra-abdominal hypertension and abdominal compartment syndrome". Critical Care Medicine 34 (2006): 2340-2348.

8. Pelosi P., et al. "Effect of intra-abdominal pressure on respiratory mechanics". Acta Clinica Belgica 62 (2007): 78-88.

9. Dalfino L., et al. "Intra-abdominal hypertension in cardiac surgery". Interactive CardioVascular and Thoracic Surgery 17 (2013): 644-651.

10. Malbrain ML and Wilmer A. "The polycompartment syndrome: towards an understanding of the interactions between different compartments!". Intensive Care Medicine 33 (2007): 1869-1872.

11. Daugherty EL., et al. "Abdominal compartment syndrome is common in medical intensive care unit patients receiving large-volume resuscitation". Intensive Care Medicine 22 (2007): 294-299.

12. O'Mara MS., et al. "A prospective, randomized evaluation of intra-abdominal pressures with crystalloid and colloid resuscitation in burn patients". Journal of Trauma 58 (2005): 10111018.

13. Hunt L., et al. "A survey of critical care nurses' knowledge of intra-abdominal hypertension and abdominal compartment syndrome". Australian Critical Care 30 (2017): 21-27.

14. Rajasurya V and Surani S. "Abdominal compartment syndrome: Often overlooked conditions in medical intensive care units". World Journal of Gastroenterology 26 (2020): 266-278.

15. Kirkpatrick AW., et al. "Pediatric Guidelines Sub-Committee for the World Society of the Abdominal Compartment Syndrome.
Intra-abdominal hypertension and the abdominal compartment syndrome: updated consensus definitions and clinical practice guidelines from the World Society of the Abdominal Compartment Syndrome". Intensive Care Medicine 39 (2013): 1190-1206.

16. Malbrain ML., et al. "Fluid overload, de-resuscitation, and outcomes in critically ill or injured patients: a systematic review with suggestions for clinical practice". Anaesthesiology Intensive Therapy 46 (2014): 361-380.

17. Rhodes A., et al. "Surviving Sepsis Campaign: International Guidelines for Management of Sepsis and Septic Shock: 2016". Critical Care Medicine 45 (2017): 486-552.

18. Kron IL., et al. "The measurement of intra-abdominal pressure as a criterion for abdominal re-exploration". Annals of Surgery 199 (1984) :28-30.

19. Jammer I., et al. "Standards for definitions and use of outcome measures for clinical effectiveness research in perioperative medicine: European Perioperative Clinical Outcome (EPCO) definitions: a statement from the ESA-ESICM joint taskforce on perioperative outcome measures". European Journal od Anaesthesiology 32 (2015): 88-105.

20. Papavramidis TS., et al. "Intra-abdominal pressure alterations after large pseudocyst transcutaneous drainage". BMC Gastroenterology 9 (2009): 42-46.

21. Malbrain ML., et al. "Results from the International Conference of Experts on Intra-abdominal Hypertension and Abdominal Compartment Syndrome ... I. Definitions". Intensive Care Medicine 32 (2006): 1722-1732.

22. Cheatham ML., et al. "Results from the International Conference of Experts on Intra-abdominal Hypertension and $\mathrm{Ab}$ dominal Compartment Syndrome. II. Recommendations". Intensive Care Medicine 33 (2007): 951-962.

23. Malbrain ML., et al. "Consensus conference definitions recommendations on intra-abdominal hypertension (IAH) and the abdominal compartment syndrome (ACS) - the long road to the final publications, how did we get there?" Acta Clinica Belgica 62 (2007): 44-59. 
24. Wendt E. "Uber den einfluss des intraabdominalen druckes auf die absonderungsgeschwindigkeit des harness". Arch Physiologische Heikunde 57. (1876): 525-527.

25. Kirkpatrick AW., et al. "Is clinical examination an accurate indicator of raised intra-abdominal pressure in critically injured patients?" C.J.S. 43. (2000): 207-211.

26. Sugrue M. "Intra-abdominal pressure". Clinical Intensive Care 6 (1995): 76-79.

27. Sugrue M and Hilman KM. "Intra-abdominal hypertension and intensive care". Yearbook of Intens. Care and Emerg. Med. /Ed by J.L. Vincent. Berlin: Springer-Verlag. (1998): 667-676.

28. Sugrue M., et al. "Temporary abdominal closure: a prospective evaluation of its effects on renal and respiratory function". Journal of Trauma 45. (1998): 914-921.

29. Timerbulatov MV., et al. "Diagnostics and treatment of ischemic reperfusion disorders in the syndrome of intra-abdominal hypertension". Khirurgiya 7. (2012): 58-63.

30. Creagh-Brown BC., et al. "Relationship between peak lactate and patient outcome following high-risk gastrointestinal surgery: influence of the nature of their surgery: elective versus emergency". Critical Care Medicine 5 (2016): 918-925.

\section{Volume 5 Issue 11 November 2021}

(C) All rights are reserved by Kryvoruchko IA and Olefir

OS. 